\title{
Sculptural reproduction of architectural ornamentation as a way for conservation of traditional craftsmanship
}

Ozlem Karakul

Suggested Citation:

Global Journal of Arts Education, 8

(c)

Abstract 


\section{Introduction}

builder's knowledge and creativity in using local building materials and handling environmental

explained safeguarding measures such as the identi

education as well as the revitalisation of the various aspects of such heritage'. In the safeguarding of

conservation of 'traditional craftsmanship'. UNESCO Living Human Treasures System

\section{Traditional Craftsmanship and the Activity of Masters in Traditional Architecture in Anatolia}

historic environments. Anatolia's historic envir

builders' of the local specifics, which are created by the mutual interrelations between environmental 
Karakul, O. (2018). Sculptural reproduction of architect ural omamentation as a way for conservation of traditional craftsman ship. Global Journal of Arts Education, 8(1), 17-27.

other side, expressive needs are related to 'mental representations' (Marchand, 2007, p. 191) and the

3. Relations Between the Disciplines of Sculpture and Architecture from the Perspective of Conservation 
Karakul, O. (2018). Sculptural reproduction of architect ural omamentation as a way for conservation of traditional craftsman ship. Global Journal of Arts Education, 8(1), 17-27.

'architectural sculpture' (Ridgway, 1996, p. 2). Throughout the Greek and Roman Period, scul pture had Caryatids 
Karakul, O. (2018). Sculptural reproduction of architect ural omamentation as a way for conservation of traditional craftsman ship. Global Journal of Arts Education, 8(1), 17-27.

Considering the UNESCO 2003 Convention and UNESCO Living Human Treasures System and Turkey's

revitalise the master's working methods which has formed through tradition in long years. In this

4.1. A specific con servation course in Department of Sculpture: Restoration of stone buildings

of the Anatolia's master craftsmen of the traditional buildings, a specific conservation course has been

4.1.1. Theoretical session/Lectures/Monumental buildings in Anatolian Seljukid Period 
Karakul, O. (2018). Sculptural reproduction of architect ural omamentation as a way for conservation of traditional craftsman ship. Global Journal of Arts Education, 8(1), 17-27.

\section{mihrabs}

of interlacing of different motifs creates an infinity effect, symbolising 'the infinity of universe' (Sagona, 2006) and 'continuity as their beginnings and ends are not clear' (Ersoy, 2008) in

\subsubsection{Practical session/Site surveys and studio work}

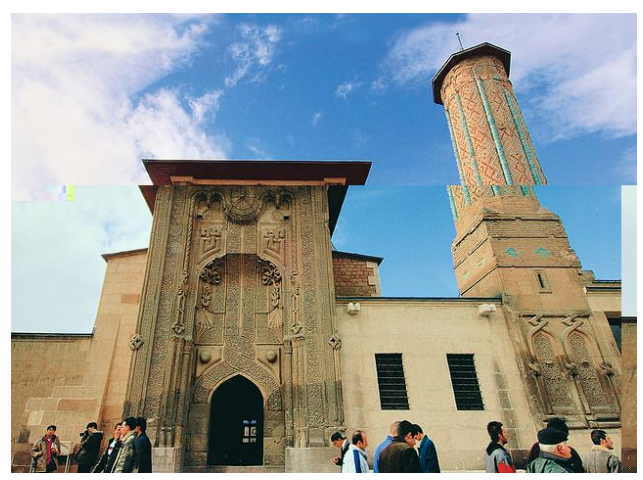

Figure 1. Ince Minareli Madrasa

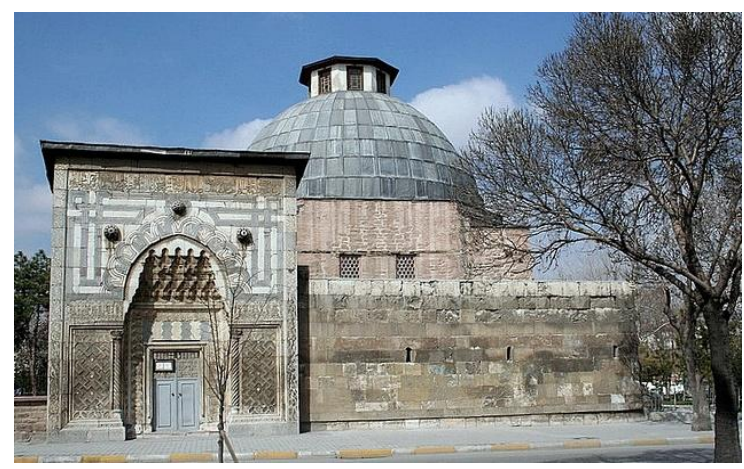

Figure 2. IKarat ay Madrasa 
Karakul, O. (2018). Sculptural reproduction of architect ural omamentation as a way for conservation of traditional craftsman ship. Global Journal of Arts Education, 8(1), 17-27.

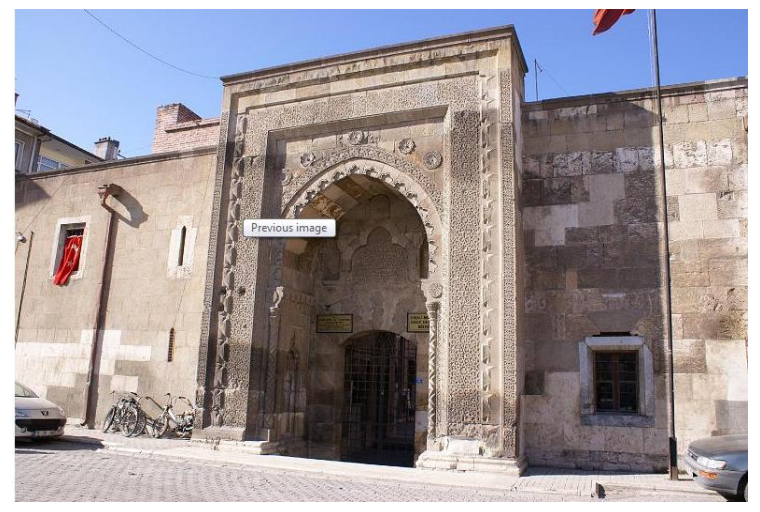

Figure 3. Sir cali Madrasa

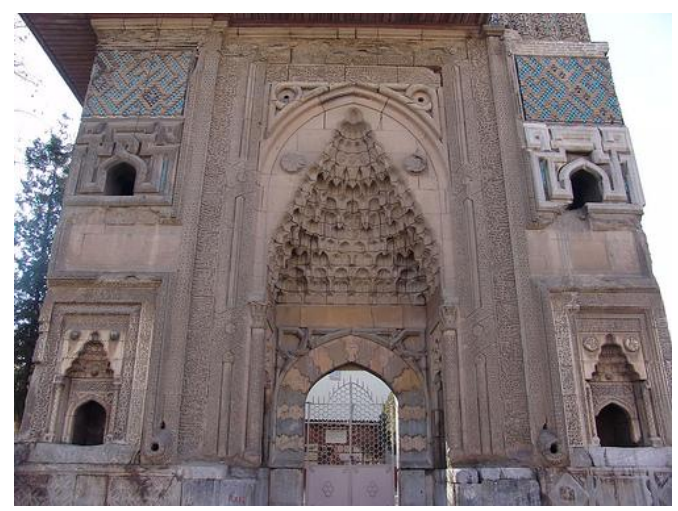

Figure 4. Sahip Ata complex

\section{Documentation:}

Analysis: 
Karakul, O. (2018). Sculptural reproduction of architect ural omamentation as a way for conservation of traditional craftsman ship. Global Journal of Arts Education, 8(1), 17-27.

\section{Reproduction:}

Reinterpretation and design:
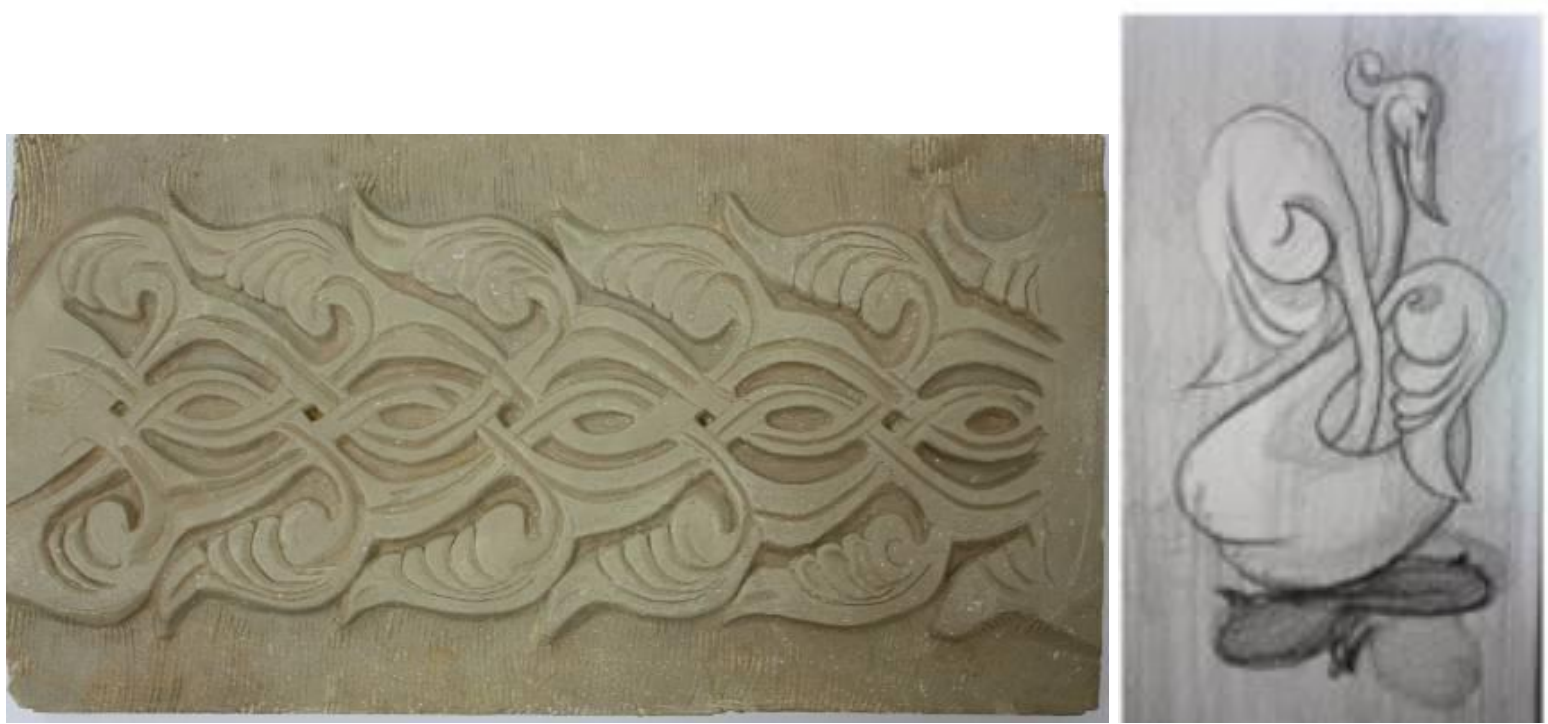

Figure 5. Reproduction and reinterpretation of the selected floral ornamentation unit on the portal of Ince Minareli Madrasa by Abdullah Gumus 

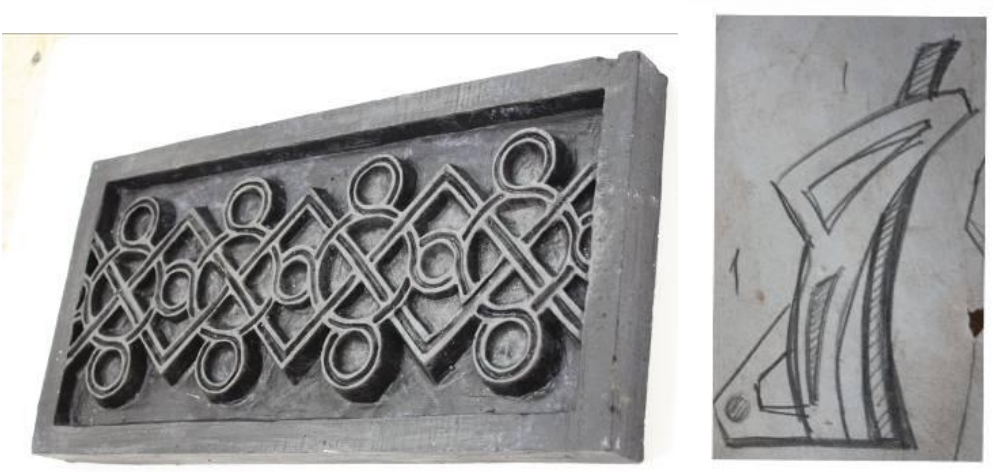

Figure 6. Reproduction of the selected geometrical ornamentation unit on the portal of Sircali Madrasa by Figen Demir
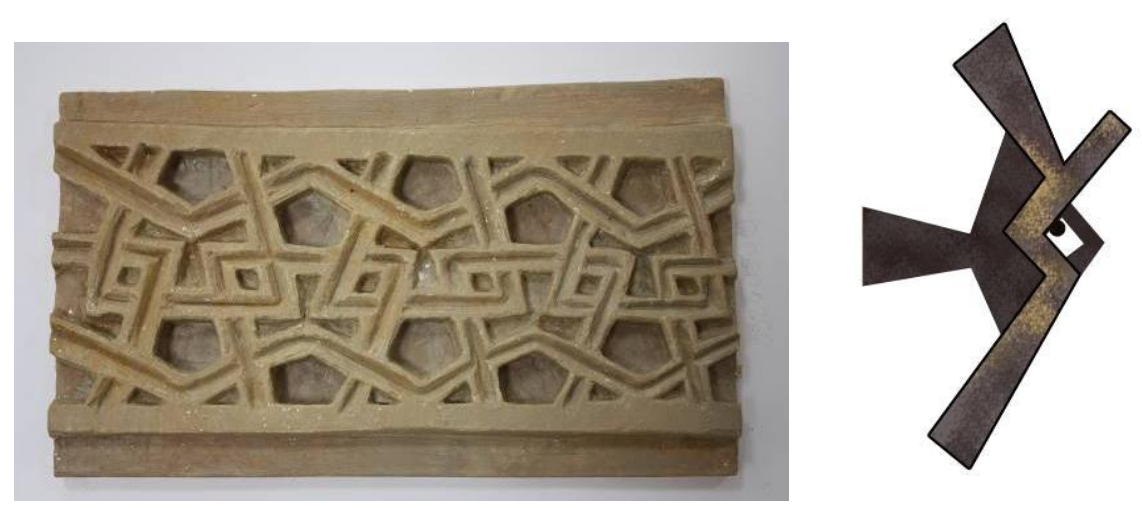

Figure 7. Reproduction and reinterpretation of the selected geometrical ornamentation unit on the portal of Sahip Ata Complex by Gulay Kaya

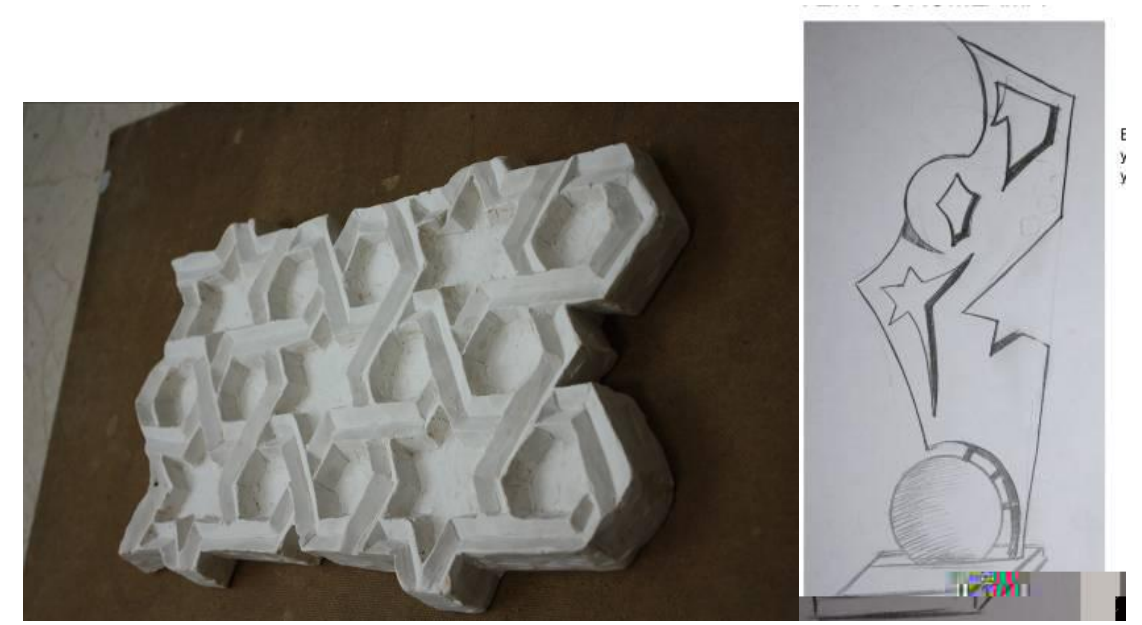

Figure 8. Reproduction and reinterpretation of the selected geometrical ornamentation unit on the portal of Sahip At a Complex by Elif Dertli 
Karakul, O. (2018). Sculptural reproduction of architectural ornamentation as a way for conservation of traditional craftsman ship. Global Journal of Arts Education, 8(1), 17-27.
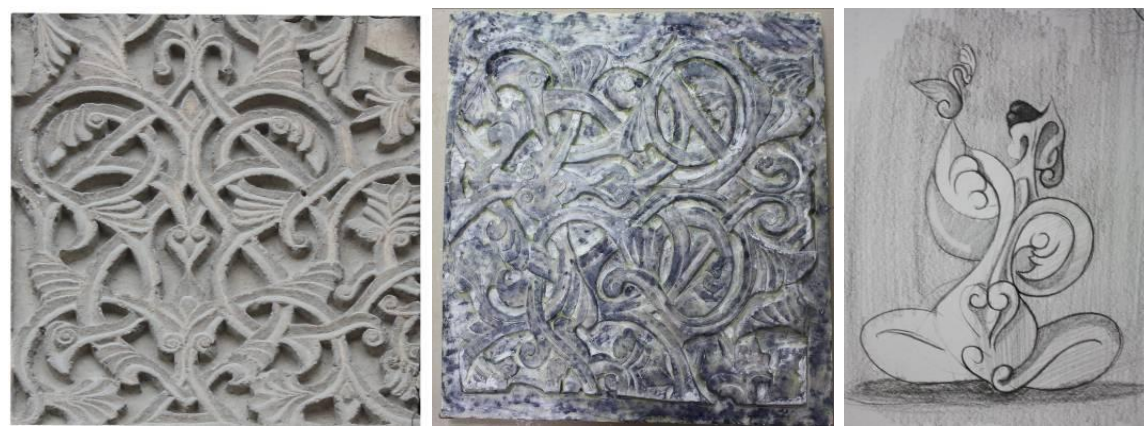

Figure 9. The selected floral ornamentation unit on the portal of Ince Minareli Madrasa and its reproduction and reinterpretation by Furkan Payas
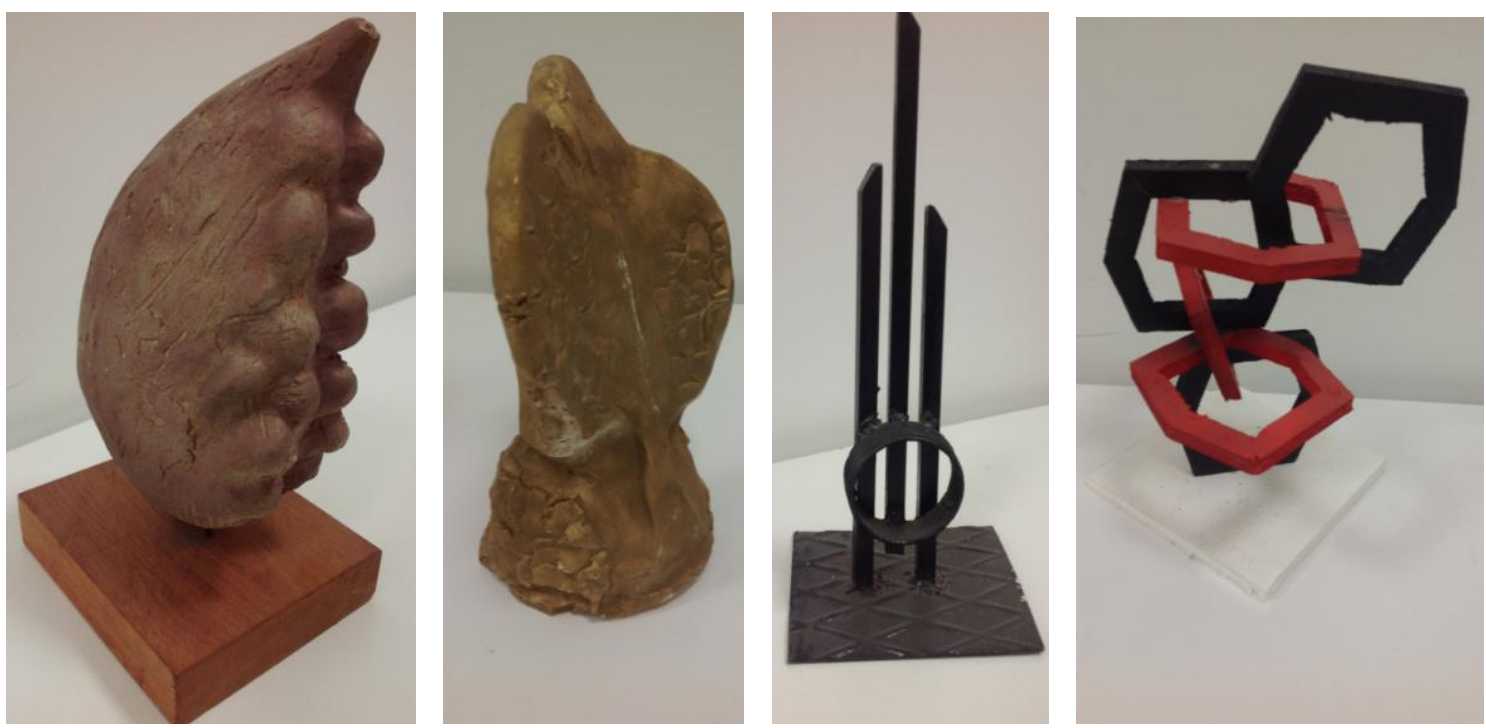

Figure 10. Three-dimensional models of the sculpture designs

\section{Conclusion}


Karakul, O. (2018). Sculpt ural reproduction of architectural ornamentation as a way for conservation of traditional craftsman ship. Global Journal of Arts Education, 8(1), 17-27.

\title{
References
}

\author{
Beyond shelter: Anatolian indigenous buildings \\ Sanat ansiklopedisi \\ Arkeolojik mimaride tas \\ Traditional Turkish arts
}

\section{Britannia, $7 \quad-$}

Journal of Architectural

Education, 32

. Cukurova Universitesi Sosyal Bilimler Dergisi, 14

A holistic approach to historic environments integrating tangible and intangible values case study: Ibrahimpasa Village in Urgup

cultural heritage

- $\quad$ Re-creating local building technology as a way for conserving intangible

Folklor-International and Quarterly Journal of Cultural Studies, 27

Selcuklu caginda Anadolu sanati

he role of 'parsing and production' in the communication of skill Ways of knowing: anthropological approaches to

crafting experience and knowledge

British Journal of Edu cational Studies, 56

Selcuklu Caginda Anadolu Sanati

Prayers in stone: Greek architectural sculpture

The art of stoneworking: A reference guide

The heritage of Eastern Turkey: from the earliest settlements to Islam

- Convention for the safeguarding of the in tangible cultural heritage 